\title{
De virus a pandemia: la lógica del valor como fundamento de la crisis sanitaria por coronavirus
}

\section{From Virus to Pandemic: The Logic of Value as the Foundation of the Coronavirus Health Crisis}

\author{
Alejandro SERRANo SÁNCHEZ \\ Facultad de Filosofía y Letras \\ Universidad Nacional Autónoma de México| México \\ Contacto: alejandroserrano@filos.unam.mx
}

\section{Resumen}

Tras la declaratoria de pandemia por coronavirus a principios del 2020, a escala mundial se ha desarrollado una vasta literatura que reflexiona sobre las causas que derivaron en la conformación de la crisis sanitaria y del papel que desempeñan las acciones humanas en la misma. En este sentido, el artículo discute sobre la compleja relación sociedad-naturaleza y, en particular, sobre la subsunción que el capitalismo ejerce sobre las prácticas humanas que, guiadas por la lógica del valor, producen un metabolismo social que manifiesta la forma en la que las sociedades modernas participan en la producción de un medio ambiente natural, cuya trama material y cultural, no posibilita el mantenimiento de la salud humana en su convivencia con los organismos que en él habitan. De esta manera, se sostiene que la actual pandemia es resultado del metabolismo social, como Marx lo llamara, que el capitalismo produce en fu afán de acumulación de valor. La dislocación que la lógica del valor introduce en la estructura de reproducción social ha conducido a la emergencia de prácticas sociales que, a través del desarrollo médico y farmacéutico, la actividad agroindustrial y agroalimentaria, asimismo el abandono de los sistemas de salud pública, entre otras, han producido un orden espacial en el que la aparición del nuevo coronavirus encontró las condiciones materiales que potenciaron su dinámica y que finalmente derivaron en la conformación de una fractura metabólica que hoy se manifiesta en forma de pandemia.

Palabras clave: lógica del valor, producción de la naturaleza, metabolismo social, fractura metabólica, pandemia 


\begin{abstract}
After the declaration of the coronavirus pandemic in early 2020, vast literature has been developed worldwide. It reflects on the causes that led to the formation of the health crisis and the role of human action. In this sense, the article discusses the complex relationship between society-nature, in particular, the subsumption that capitalism exercises on human practices that, guided by the logic of value, produce a social metabolism that manifests how modern societies participate in the production of a natural environment, whose material and cultural order does not guarantee human health in its coexistence with the organisms that inhabit it. In this way, it is argued that the current pandemic results from the social metabolism that capitalism produces in its desire to accumulate value. The dislocation that the logic of value introduces into the structure of social reproduction gave rise to the emergence of social practices. Through medical and pharmaceutical development, agro-industrial and agro-food activity, as well as the abandonment of public health systems, among others, have produced a spatial order in which the emergence of the new coronavirus found the material conditions that enhanced its dynamics and finally led to the formation of a metabolic fracture that today manifests itself in the form of a pandemic.
\end{abstract} Keywords: logic of value, production of nature, social metabolism, metabolic fracture, pandemic

\title{
Introducción
}

Desde diciembre de 2019 y tras la aparición de los primeros brotes del coronavirus en la ciudad de Wuhan, China, organismos internacionales como la Organización Mundial de la Salud (oms) en sincronía con diversos gobiernos nacionales, han abogado por la elaboración de programas políticos de enfrentamiento a la pandemia que, en términos generales, manifiestan una severa contradicción entre lo que se debe y lo que se puede hacer ante la emergencia sanitaria, ya que si bien, por un lado, dichos programas han estado dirigidos a prevenir los contagios con vistas al mantenimiento de la vida humana a través del confinamiento en casa, el distanciamiento social y la suspensión de actividades no esenciales, por otro lado, dichas medidas se diseñan y articulan en función de una racionalidad económica que presiona por un rápido retorno de los procesos económicos, según se nos dice, con el objetivo 
de evitar una dramática interrupción en las cadenas productivas globales, una caída grave de los niveles de producción y de consumo de bienes y servicios, así como una devaluación importante de diversos activos y, por lo tanto, la aparición de una crisis económica generalizada.

La presión que hoy en día ejercen los gobiernos locales para reactivar la cotidianidad precedente y las actividades económicas a través de lo que se ha dado en llamar la "nueva normalidad", más que ser parte de una estrategia diseñada para frenar el avance del coronavirus, lo cierto es que aparece como una medida desesperada para no interrumpir por más tiempo los ciclos de producción, distribución y de consumo necesarios en el proceso de valorización que impone la forma social dominante, situación que ya ha generado la aparición de rebrotes en prácticamente todo el mundo y que se perfilan como el inicio de nuevas oleadas de contagios.

Bajo este panorama, parece paradójico pensar que en medio de la pandemia que estamos viviendo las medidas destinadas a la protección de la salud pública estén condicionadas o mediadas por determinados procesos económicos. No obstante, como nos recuerda Smith (2006), vivimos un modo de existencia en el que "la reproducción de la vida material es por completo dependiente de la producción y reproducción del plusvalor" (35). Si bien se reconoce que en el momento actual la reproducción de la vida y la salud dependen de la reproducción del capital, ello de ninguna manera significa que la reproducción del capital tenga como fundamento la preservación de la salud y la vida, lo anterior se hace evidente cuando advertimos que millones de personas a lo largo del mundo se encuentran en una disyuntiva entre quedarse en casa con la posibilidad de perder su fuente de ingresos o salir a la calle para preservar su empleo pero con la posibilidad de contagiarse y perecer. De esta manera, no solo para empresarios y gobiernos, sino sobre todo para trabajadores y población en general, la demanda por la reactivación de las actividades económicas surge como una presión social que en su búsqueda de subsistencia se contrapone a la subsistencia misma.

En este sentido, la evidente contradicción entre salud y economía puede parecer el resultado de una situación coyuntural derivada de la crisis sanitaria que hoy se experimenta a escala planetaria. Sin embargo, es posible afirmar que dicha contradicción, más que una mera coyuntura, corresponde a una especificidad propia de las formas sociales en la modernidad capitalista, de tal manera que representa una expresión de aquello que Bolívar Echeverría (1998) identificaba como 
la contradicción entre vida y capital, o entre valor de uso y valor. De hecho, sostenemos que el origen y desarrollo de la pandemia del SARS-CoV-2 está íntimamente ligado con el despliegue de un conjunto de relaciones o prácticas sociales cuya dinámica y sentido responden a la lógica del valor, esto es, a la racionalidad económica y mercantil en tanto fundamento que se impone sobre la reproducción de la vida social.

Desde esta perspectiva, el presente artículo tiene por objeto mostrar que la actual situación de pandemia no es la consecuencia de un "proceso natural" entendido éste como una irrupción biológica extraordinaria que inevitablemente debe afectar negativamente a la especie humana en tanto que ser viviente sobre el planeta. Por el contrario, sostenemos que la crisis sanitaria es el resultado de una producción social tanto a nivel del metabolismo social-natural históricamente producido como condición de existencia de la vida humana, pero también, y más importante aún, de la distorsión o ruptura de este metabolismo mediante la irrupción histórica de las relaciones de producción capitalistas en el que las prácticas humanas, sometidas a la lógica del valor - tanto en su hacer y su no-hacer, como en su sentido y sus consecuencias-, configuraron ciertas condiciones simbólicas y materiales que le permitieron al coronavirus convertirse en pandemia.

Para tal propósito será necesario reflexionar, en un primer momento, sobre la manera en que el materialismo histórico piensa la relación sociedad-naturaleza y cómo a partir de ella construye una unidad histórica social-natural en el que se entiende que las relaciones sociales encaminadas a garantizar la reproducción humana y social son simultáneamente relaciones naturales, al tiempo que los procesos y leyes naturales adquieren y determinan formas sociales.

Lo anterior nos permitirá reflexionar, en un segundo momento, sobre la alteración o malformación del metabolismo social-natural en el que se están produciendo directa e indirectamente condiciones socioambientales que nos vulneran y nos ponen en riesgo frente al actuar de diversos patógenos y virus. Es en el proceso de enajenación que la lógica del valor hace de la del valor de uso en donde podemos encontrar la clave teórica para comprender cómo el sentido o lógica de determinadas prácticas sociales configuran una fractura metabólica que hoy se expresa como la producción de una pandemia. 


\section{La naturaleza del coronavirus dentro del metabolismo social-natural}

Dentro del lenguaje cotidiano como también dentro de gran parte del discurso científico dominante, las concepciones sobre la relación sociedad-naturaleza han tendido a descansar sobre un dualismo cartesiano que, a nivel epistemológico, entiende a la sociedad y a la naturaleza como dos esferas autónomas, en las que si bien se reconocen ciertas relaciones causales, cada una se define por sus propios procesos y, por lo tanto, se desenvuelven con independencia la una de la otra: lo "natural" como creación de la naturaleza en oposición a lo "artificial" como producto de la actividad humana. Visto así, hablar de la producción de la naturaleza, y más aún, hablar de la naturaleza como producto de la acción humana representa para el pensamiento dominante una aberración filosófica en tanto que ésta "es entendida precisamente como aquello que no puede ser producido; es decir, la antítesis de la actividad humana productiva" (Smith, 2006: 13).

La desvinculación que el pensamiento dominante hace de la naturaleza y de la sociedad conduce a una reafirmación de la pureza de estas dimensiones en la cual la naturaleza de ninguna manera condiciona o determina a las prácticas sociales, como tampoco la sociedad produce, media o condiciona los procesos y formas naturales. De este modo, prevalece la idea generalizada de que mientras, por un lado, el actuar de plantas y animales - como el castor que crea pantanos mediante la construcción de represas en las que habita o la abeja que a través de la polinización favorece la vida vegetal - es reconocido como un proceso natural que tiene como resultado la creación de ecosistemas o ambientes naturales de los que forman parte; por otro lado, la acción práctica, o incluso subjetiva, de la especie humana - como la construcción de viviendas, carreteras o jardines; la producción de medicamentos; la creación artística; así como la edificación de represas o ciudades - es vista como un proceso que escapa de lo natural, llegando incluso a considerarse como un proceso que irremediablemente está destinado a invadir y destruir ecosistemas.

En el caso de los virus, se suele afirmar que las enfermedades y epidemias que experimenta la especie humana constituyen el resultado de un proceso natural que deriva del patrón de comportamiento y reproducción de estos 
organismos. ${ }^{1}$ Actualmente se sabe que los virus son agentes importantes en el proceso evolutivo de muchas especies, incluida la humana, caracterizándose por un comportamiento constante de mutación que los lleva a transferirse de huésped en huésped a través de los mecanismos de contagio que encuentran. Si bien su replicación celular en determinadas especies puede implicar un daño a la salud en ciertos individuos, ello no significa que dicha afección se traduzca automáticamente en un problema de salud pública $\mathrm{y}$, en consecuencia, la constitución de una pandemia. De esta manera, si se considera a las pandemias como algo que ocurre de forma natural, implícitamente se sostendría que las enfermedades y las muertes relacionadas con el comportamiento de los patógenos son un destino biológico que ocurre y ocurrirá con independencia de nuestros hábitos de consumo; de nuestras maneras culturales de convivir, de saludarnos, de relacionarnos; de nuestros sistemas de salud, de transporte y de información; así como de nuestros intereses y relaciones de poder en el desarrollo médico, científico y tecnológico. En última instancia, ello no nos permitiría explicar por qué las pandemias se han extendido de forma desigual, afectando diferencialmente tanto a los territorios como a los distintos grupos sociales.

Frente a este dualismo cartesiano, surge la necesidad de comprender no sólo el lugar que ocupan las prácticas humanas dentro del mundo natural, sino también los efectos y consecuencias que tiene la transformación del mundo natural en el mundo social. En este sentido, las perspectivas críticas en torno al materialismo histórico nos enseñan que la relación sociedad-naturaleza se constituye sobre una dialéctica que tiene como punto de partida el intercambio material que surge del proceso de trabajo. Este intercambio material no se limita a un simple tomar y devolver — como lo postulan una parte importante de los representantes

${ }^{1}$ Al respecto, Andrés Moya y Fernando Baquero (2015), en un artículo señalan que "las epidemias forman parte de la naturaleza" en tanto que representan procesos de interacción entre poblaciones que se han dado a lo largo de la historia evolutiva en el planeta. Desde esta perspectiva, implícitamente sostienen que, si las epidemias son consideradas como algo no natural, ello se debe a que nuestros conocimientos y análisis sobre los efectos benéficos de las epidemias "están sesgados" toda vez que "hay muchos más datos de casos problemáticos que de casos normales". De esta manera, al asumir que "hay muchísimas más 'epidemias beneficiosas' de las que apenas somos conscientes, pero cuyo desconocimiento ha impedido una valoración científica de la realidad" (Moya y Baquero, 2015: 13), concluyen que el carácter natural de las epidemias obedece a que "normalmente" éstas suelen tener más efectos benéficos que dañinos. 
de la Economía Ecológica-; por el contrario, de este intercambio procede una transformación cualitativa de la realidad material en tanto que nueva condición sobre la que la sociedad y la naturaleza operan como una unidad histórica, en un proceso constante que Marx denominó metabolismo social. Consiste, pues, en un proceso mucho más complejo en el que las formas sociales, condicionadas por el mundo natural, retornan a la naturaleza mediante el trabajo y se funden con ella. Foster (2013) lo explica de la siguiente manera:

La humanidad, a través de su producción, "extrae" sus valores de uso naturales y materiales de ese "metabolismo universal de la naturaleza", al mismo tiempo "insuflando una (nueva) vida" a estas condiciones naturales "como elementos de una nueva formación (social)", generando por ese motivo una especie de segunda naturaleza. Sin embargo, en una economía mercantil capitalista esta segunda naturaleza asume una forma alienada, dominada por el valor de cambio antes que por el valor de uso, conduciendo a una fractura en este metabolismo universal. (4)

Si bien en la cita anterior Foster ya plantea la peculiaridad y las consecuencias que le imprime la lógica capitalista al metabolismo social, debemos destacar, en un primer momento, que la forma abstracta de dicho metabolismo implica una relación dialéctica a partir de la cual se puede comprender que "la naturaleza y la sociedad son dos partes constitutivas de una sola unidad histórica, la unidad social-natural de una misma realidad material" (León, 2016: 103). El metabolismo social es visto aquí como un proceso de autodeterminación material en el sentido de que el desenvolvimiento o reproducción de las formas sociales sólo es posible a través de la naturaleza y de la transformación de la misma que procede al proceso de trabajo. Pero también de autodeterminación de la propia naturaleza en tanto que las prácticas humanas producen una realidad material que condiciona el desenvolvimiento del mundo natural. Ya Marx (2010) planteaba la cuestión de la siguiente manera:

El trabajo es, en primer término, un proceso entre la naturaleza y el hombre, proceso en que éste realiza, regula y controla mediante su propia acción su intercambio de materias con la naturaleza. En este proceso, el hombre se enfrenta como un poder natural con la materia de la naturaleza. Pone en acción las fuerzas naturales que forman su corporeidad, los brazos y las piernas, la cabeza y la mano, para de ese 
modo asimilarse, bajo una forma útil para su propia vida, las materias que la naturaleza le brinda. Y a la par que de ese modo actúa sobre la naturaleza exterior a él y la transforma, transforma su propia naturaleza. (130; cursivas nuestras)

Como bien observó Marx (2010), en este nivel abstracto del metabolismo social, la actividad productiva de la especie humana no se distingue de la actividad transformadora de la naturaleza que llevan a cabo el resto de las especies. En el proceso de reproducción de su existencia, cada ser vivo sobre el planeta despliega un conjunto de actividades que inevitablemente transforman su entorno material inmediato y cuya consecuencia es la producción de un medio ambiente favorable a su propia subsistencia. Así como la abeja y el castor, la humanidad interviene sobre la naturaleza, modelándola según sus necesidades y tratando de garantizar y facilitar la reproducción de su especie. En este proceso, cada una de ellas se vale de sus fuerzas naturales que en cada momento son dotadas por la naturaleza en virtud de un proceso evolutivo en constante transformación.

Visto desde esta perspectiva, no existe una naturaleza o un medio ambiente natural ontológicamente dado ni mucho menos una naturaleza ideal o romántica como pretenden algunos seguidores del movimiento ambientalista. Por el contrario, la naturaleza es materia histórica, es decir, materia en constante proceso de transformación. Dicho de otra manera, la naturaleza es materialidad en movimiento permanente y es modelada no sólo por las fuerzas geológicas, atmosféricas, climáticas, astronómicas, químicas y biológicas, sino también por la coparticipación del trabajo humano en tanto fuerza natural y cada vez en mayor escala conforme se desarrollan sus fuerzas productivas. ${ }^{2}$ La participación que ha tenido la actividad humana en la producción de la naturaleza es actualmente de tal magnitud que tiene presencia tanto a escala planetaria como a nivel genético y es por ello que Marx afirmaba con razón que "la naturaleza que precedió a la historia humana $[\ldots]$ ya no

${ }^{2}$ El hecho de que existan actualmente entornos naturales sin ningún tipo de presencia humana no invalida de ninguna manera el planteamiento central de la producción de la naturaleza. Al respecto, Smith (2006) sostiene que "Donde la naturaleza sobrevive inalterada, kilómetros bajo la superficie terrestre o años luz hacia delante, lo hace únicamente porque aún resulta inaccesible. Si es necesario, podemos dejar que esta naturaleza inaccesible sostenga nuestras nociones de una naturaleza idílica, pero ésta será siempre una naturaleza ideal, abstracta, producto de la imaginación, una naturaleza que jamás conoceremos. Los seres humanos han producido la totalidad de la naturaleza que hasta ahora les ha sido accesible" (46). 
existe absolutamente en ninguna parte (excepto quizás en unas cuantas islas coralinas australianas de reciente formación)" (Marx en Smith, 2006: 42).

Así pues, esta noción del metabolismo social nos permite comprender que los ecosistemas son la síntesis material de múltiples fuerzas naturales biológicas, físicas y químicas dentro de las cuales participa la especie humana y que hoy tiene alcances globales. Si bien sabemos que con el hundimiento de un barco podemos participar en la construcción de un ecosistema en forma de arrecife de coral, ello no significa que con el conjunto de las prácticas humanas estemos plenamente conscientes del tipo de ecosistemas que estamos construyendo, ni tampoco si éstos pueden tener efectos adversos a nuestra salud o poner en entredicho la reproducción de otras especies. Cada formación social ha producido su propio ecosistema y lo ha hecho de acuerdo con el umbral de posibilidades intelectuales y materiales que encuentra en cada momento histórico.

De este modo, los ecosistemas sobre los que han surgido, desarrollado y mutado los virus son en parte el resultado de nuestro actuar, conciente o inconciente, y de forma directa o indirecta, sobre la materia natural. De hecho, es muy probable que el calentamiento global por efecto de la actividad humana esté en proceso de transformación de nuevos ecosistemas en los que se deben estar desarrollando nuevos virus y patógenos, e incluso, se ha llegado a plantear la posibilidad de que el patrón de comportamiento (la letalidad y nivel de contagio) del nuevo coronavirus es el resultado de procedimientos genéticos hechos en laboratorio. Más allá de estas dudas razonables que de hecho ponen en evidencia la posibilidad que tiene la acción humana como productora de naturaleza, lo cierto es que los análisis científicos muestran que dichas características no son el resultado de ensayos en laboratorio, sino de procesos naturales sin intervención humana directa - tal como ha ocurrido con otros virus relacionados con epidemias a lo largo de la historia humana-, cuestión que, por otro lado, no niega la posibilidad de que estas características sean el producto indirecto o la consecuencia de ciertos procesos sociales.

En este sentido, la producción de la naturaleza por parte de la humanidad es un proceso del que apenas somos conscientes pero cuyas consecuencias o resultados no deseados nos advierten cada día sobre los impactos que tienen las prácticas sociales como determinantes del mundo natural, pero que no por ello debemos de interpretarlas como meras acciones destinadas a destruir ecosistemas; por el contrario, éste es un proceso abierto que bien podemos dirigir racionalmente con vistas a la 
configuración de un metabolismo social-natural con la capacidad de sustentar el conjunto de las formas de vida sobre el planeta.

Si bien hemos mencionado que la actividad humana productiva, dentro de la unidad social-natural, representa la condición mediadora que hace posible la conformación de la realidad material, esta perspectiva no impide el reconocimiento de una cierta autonomía de la naturaleza y de los patrones de comportamiento que la definen, puesto que precisamente es a partir de ésta que se hace posible la propia actividad humana. Reconocer que la humanidad produce sus propias condiciones objetivas de trabajo no significa reconocer que ésta puede transgredir o violar la legalidad natural inherente a la propia dinámica de la naturaleza. Como nos recuerda Foster (2013), los seres humanos transforman la naturaleza, "pero no lo hacen como les plazca, sino bajo las condiciones heredadas del pasado (de la historia natural y social), y siguen dependiendo de la dinámica básica de la vida y la existencia material" (4). Siguiendo este mismo razonamiento, León (2016) señala:

Esta unidad social-natural es constituyente de la existencia material social, pero no se limita a considerar la objetivación de la práctica social en la naturaleza, ni a ésta última como un mero espejo material de su propia práctica; además reconoce cierta legalidad natural en la materia, patrones naturales de comportamiento que en cierto sentido mantienen su autonomía respecto de las prácticas sociales históricas y de las intenciones humanas que las acompañan. Pero no por ello es una legalidad aislada del sujeto, ni mucho menos socialmente neutral o transparente. (104).

Así pues, el entendimiento de la naturaleza de los virus debe involucrar el reconocimiento no solo del patrón de comportamiento inherente a la dinámica del mundo natural, sino, además, de la articulación de este comportamiento con las prácticas sociales que lo van redefiniendo históricamente. En este sentido, si bien se sabe que las enfermedades zoonóticas, como es el caso del actual COVID-19, son una consecuencia del comportamiento propio de estos organismos, dicho comportamiento no se encuentra aislado de los procesos sociales en tanto que es precisamente el cuerpo humano y su entorno material los que constituyen el ecosistema del virus. El entorno natural transformado y producido a través del trabajo humano es el mismo en el que el virus participa y desarrolla su actividad. Por lo tanto, su dinámica biológica, es decir, sus procesos mutativos, sus formas de transmisión, de reproducción, de sobrevivencia, etcétera, se articulan dialécticamente con las 
condiciones culturales y materiales que se van produciendo histórica y socialmente y que, por lo tanto, configuran un ecosistema del que depende y cuyas condiciones pueden potenciar o limitar su dinámica.

Es en la unidad social-natural en la que las condiciones materiales, producidas por la acción humana, se constituyen como la naturaleza del virus; o dicho de otra manera, la realidad material que se sintetiza en el metabolismo social es el ecosistema del virus y en él se descubre que nuestros medios de transporte son sus medios de dispersión; que nuestras formas culturales de convivencia, de relaciones interpersonales y nuestros hábitos de consumo son sus formas de contagio; que nuestras mascotas y otros animales de crianza son sus reservorios; y que nuestra ausencia de cuidados sanitarios, nuestra ignorancia y desinformación son su carta de invitación a nuestros cuerpos. Es de esta manera que la naturaleza de los virus adquiere forma social y es por esta razón que sostenemos que las epidemias o pandemias son producidas socialmente.

Las crisis sanitarias relacionadas con los virus han estado presentes en la historia natural de la humanidad por millones de años, lo que confirma que "la especie humana intercambia microorganismos desde hace mucho tiempo con su entorno animal no humano" (Moutou, 2020: s. p.). Hoy es fácil comprender que cuando las epidemias ocurrían en épocas anteriores de la historia éstas se debían al desconocimiento de las leyes y de los patrones de comportamiento naturales y, por lo tanto, a la configuración de metabolismos sociales incapaces de hacer frente a esta problemática $\mathrm{y}$, pese a ello, nunca llegaron a tener un alcance global dadas las limitaciones en los medios de transporte y por las estructuras espaciales caracterizadas por la dispersión poblacional en reducidos núcleos humanos.

Actualmente queda perfectamente claro que la ciencia no conoce la totalidad del universo viral con el que convivimos cotidianamente; no obstante, el desarrollo médico, científico y tecnológico del último siglo tiene hoy el potencial de configurar un metabolismo social que podría evitar el surgimiento de pandemias o crisis sanitarias a través del desarrollo de la medicina veterinaria, las vacunas, la prevención de enfermedades y el mejoramiento de los sistemas de salud pública. Así pues, si en la época moderna se siguen experimentando epidemias como la del SARS-COV-2, el ébola o el VIH, ${ }^{3}$ éstas ya no se deben a un simple desconocimiento de las maneras de

3 En una entrevista realizada al Dr. Eduardo López-Collazo, director del Instituto de Investigación Hospital Universitario La Paz, España, sobre la pandemia del VIH, éste señala que si bien el desarrollo de 
actuar de estos patógenos, sino que obedecen a un proceso social, alienante, que subsume a nuestras relaciones sociales y prácticas productivas y que las obliga a reproducirse pese a que sabemos que son éstas las que directa o indirectamente están ocasionando el surgimiento de estas crisis. Lo anterior nos lleva a cuestionarnos cuáles son estas prácticas; qué proceso las subsume y de qué manera están distorsionando el metabolismo social.

\section{La pandemia como fractura metabólica en su especificidad capitalista}

En su ensayo titulado La cruel pedagogía del virus, Boaventura de Sousa Santos (2020) plantea cómo la actual pandemia del coronavirus constituye una manifestación del modelo de sociedad que se viene imponiendo desde el siglo XVII, esto es, una sociedad capitalista marcada por una racionalidad económica y mercantil cuyos intereses cristalizan en una institución omnipresente y todopoderosa: el mercado. Así, después de reflexionar sobre Dios y el virus como entidades invisibles y poderosas, el autor escribe:

En los últimos tiempos ha surgido otro ser todopoderoso invisible, ni grande ni pequeño, pero deformado: los mercados. Al igual que el virus es insidioso e impredecible en sus mutaciones y, como dios [...] es uno y muchos. Se expresa en plural, pero es singular.

A diferencia de dios, el mercado es omnipresente en este mundo y no en el más allá. Y, a diferencia del virus, es una bendición para los poderosos y una maldición para todos los demás [...].

fármacos antirretrovirales durante los años noventa significó un paso importante hacia el tratamiento de esta enfermedad, el objetivo de las investigaciones sigue estando en el desarrollo de una vacuna para erradicar al virus. Así mismo, sostiene que si hoy no existe tal vacuna, esto se debe, en parte, a "que se hayan encontrado esos fármacos tan efectivos para salvar al paciente y tener una vida normal, lo que ha hecho que disminuya la inversión sobre la investigación en la vacuna", y concluye, "por eso se estudian los fármacos actuales y no tanto las vacunas [...], hay un interés económico detrás porque el medicamento se toma toda la vida, mientras que la vacuna una vez" (Europa Press, 2020: s.p.). 
Sujeto a tantos seres invisibles y todopoderosos, el ser humano y toda la vida no humana de la que depende son inminentemente frágiles. (De Sousa Santos, 2020: 32-33)

¿En qué sentido la sujeción de la vida en general al mercado puede significar una situación de fragilidad humana tal como la experimentamos hoy bajo la pandemia? Así mismo, ¿En qué consiste la deformidad del mercado y cómo éste puede ser insidioso e impredecible para la reproducción social? A nuestro parecer, la respuesta a estas cuestiones tiene que ver con la dinámica propia de la reproducción de la forma social contemporánea y, en particular, de la lógica del valor - lógica que gobierna al mercado - que subyace en la dinámica de reproducción del capital.

Como toda formación social, la sociedad capitalista produce y conforma un determinado metabolismo social que, a diferencia de los modos de producción que le precedieron, tiene como fundamento la acumulación de capital lo que, por lo tanto, implica la configuración de nuevas prácticas sociales que al producir un orden espacial (material y culturalmente) enfocado a la acumulación, simultáneamente produce un régimen metabólico acorde con este propósito. Esto es lo que Harvey (2014) nos enseña cuando señala que "el capital es un sistema ecológico en constante funcionamiento y evolución dentro del cual tanto la naturaleza como el capital se producen y reproducen continuamente" (242), y plantea, además, que el "ecosistema está construido a partir de la unidad contradictoria de capital y naturaleza, de la misma manera que el capital es una unidad contradictoria de valor de uso (su forma material y "natural") y valor de cambio (su valor social)" (243).

La valorización del valor como principio organizador consiste, pues, en un proyecto político de organización social en el que la acumulación de valor se presenta no sólo como un fin en sí mismo, sino como una necesidad social (abstracta), históricamente impuesta $\mathrm{y}$, por lo tanto, como un proceso que penetra en todos los poros de la vida en sociedad. Se trata pues de una lógica que subsume el proceso de reproducción social y que lo obliga a desarrollar (o mejor dicho, a distorsionar) su sistema de capacidades de producción (sus fuerzas productivas) y su sistema de necesidades de consumo conforme a las necesidades del mercado y del capital y no del propio cuerpo social. De este modo, ya no es la sociedad la que determina qué se produce - lo que tendría que estar en función del conjunto de necesidades 
existentes, tanto individuales como colectivas, en un momento histórico particular (tipo de alimentación, de vestimenta, calidad de la salud, solución de conflictos ecológicos, etcétera) - ; sino que ahora es el mercado el que determina cómo, cuánto y qué se produce en virtud de aquello que posibilita de mejor manera la acumulación. ${ }^{4}$ Que una determinada sociedad tenga como propósito la creación de plusvalía y la acumulación de capital (forma del valor de la reproducción social) por sobre la satisfacción de las necesidades concretas que exige el mantenimiento de la vida (forma natural de la reproducción social), es lo que representa, para Echeverría, la contradicción entre valor y valor de uso, contradicción de la cual se desprenden todos los otros conflictos o absurdos que se manifiestan en la cotidianidad de la época contemporánea, como por ejemplo, la crisis ecológica y sanitaria. Así, esta contradicción básica o fundamental del capitalismo consiste

en que los seres humanos sólo pueden producir y consumir bienes, crear riqueza y gozarla o disfrutarla, es decir, sólo están en capacidad de autorreproducirse, en la medida en que el proceso de producción y de consumo de sus bienes sirve de soporte a otro proceso diferente que se le sobrepone y al que Marx denomina "proceso de valorización del valor" o "acumulación de capital". [...]. Si los seres humanos existen de la manera absurda en que podemos constatar empíricamente - en medio de opresiones, represiones, explotaciones, todas ellas evitables en principio-, es porque su proceso natural de reproducción no obedece a un telos propio capaz de sintetizarlo sino a uno ajeno - enajenado-que es el telos "cósico" del valor instalado como sujeto que se autoafirma, que se valoriza: el telos de la acumulación de capital (Echeverría, 1998: 9-10).

4 En su reflexión sobre la contradicción entre valor de uso y valor, inmersa en la mercancía, Echeverría muestra cómo la lógica del valor distorsiona el proceso de reproducción social y, por lo tanto, éste orienta su sistema de capacidades de producción a operar conforme a la lógica mercantil. En este sentido, el autor señala que, de acuerdo con Marx, las cosas "son producidas y consumidas en la sociedad mercantil pura, no de acuerdo a un determinado plan, siguiendo un determinado proyecto, u obedeciendo a una determinada necesidad, sino que son producidas de acuerdo a la casualidad; son producidas porque en el momento anterior del mercado demostraron un comportamiento más o menos bueno en tanto que productos mercantiles. Si se vendieron bien entonces, ahora esas cosas se producirán en mayor cantidad; pero si no se vendieron bien, entonces deberán alterarse cuantitativa y/o cualitativamente: su presencia objetiva sigue un destino completamente azaroso" (Echeverría, 1998: 19). 
De esta manera, para Echeverría, la sociedad capitalista es una sociedad alienada y alienante, por una lógica que persigue el lucro o la ganancia antes que la vida. Se trata, pues, de una sociedad en la que el sentido de sus prácticas productivas, en primera instancia, ya no obedecen a la voluntad del propio sujeto social en su deseo de reproducción de la vida humana, sino que ahora obedecen a un proceso ajeno que domina y orienta dichas prácticas con el deseo de reproducir el capital. Visto así, bajo el ecosistema que crea el capital, "la lógica de la mediación social [ya] no es la simple racionalidad que surge inmediatamente de la necesidad de producir y consumir valores de uso, [...]. Es, mejor dicho, la lógica abstracta unida a la creación y la acumulación de valor social lo que determina la relación con la naturaleza en el capitalismo" (Smith, 2006: 35).

Es en este sentido que, al enajenar el conjunto de las prácticas sociales, la sociedad capitalista está produciendo un metabolismo social-natural igualmente enajenado, es decir, produce un ecosistema que al modelarse de acuerdo a la dinámica que exige la acumulación, tiende a moldear constantemente de forma negativa los patrones de comportamiento del mundo natural y, por lo tanto, a generar un conjunto de condiciones materiales, ambientales y ecológicas, que distorsionan el metabolismo social y que consecuentemente atrofian no sólo la capacidad y la posibilidad de la especie humana para reproducirse socialmente en forma digna, sino también al conjunto de las formas de vida para subsistir. Harvey (2020), reflexionando sobre la actual pandemia, lo explica de la siguiente manera:

El capital modifica las condiciones medioambientales de su propia reproducción, pero lo hace en un contexto de consecuencias involuntarias (como el cambio climático) y con el trasfondo de fuerzas evolutivas autónomas e independientes que andan perpetuamente reconfigurando las condiciones ambientales. Desde este punto de vista, no hay nada que sea un desastre verdaderamente natural. Los virus van mutando todo el tiempo, a buen seguro. Pero las circunstancias en las que una mutación se convierte en una amenaza para la vida dependen de acciones humanas. (s. p.)

Desde el punto de vista de la vida y la reproducción social, la lógica del valor se expresa como un sinsentido de las prácticas sociales. Al enajenarse de la vida, las múltiples prácticas humanas entran en conflicto constantemente con la vida misma, puesto que su sentido y su motor es otro: el de la acumulación. Marx, como lo 
muestran sus preocupaciones sobre la renta de la tierra y la degradación química del suelo, era plenamente consciente que la subsunción de las prácticas sociales bajo el capitalismo irremediablemente conducía al deterioro de las condiciones naturales que de vez en vez estallan en procesos que directamente ponen en entredicho la reproducción social. Esta desarmonía que surge en la relación metabólica entre la sociedad y la naturaleza, es decir, cuando el ecosistema que produce la especie humana ya no puede garantizar la reproducción de la misma especie, es lo que Marx entendía como la fractura metabólica (Saito, 2017).

De esta manera y como lo dijimos anteriormente, la ocurrencia de fracturas metabólicas bajo el capitalismo ya no surgen por un simple desconocimiento de las leyes y dinámicas naturales, como tampoco del desconocimiento de las consecuencias que tienen las acciones humanas en determinados ámbitos. Actualmente es bien sabido que la deforestación indiscriminada es la causa principal de la desertificación y de la erosión de los suelos; que la configuración técnica de la matriz energética vigente a nivel mundial, dependiente de energías fósiles, es la causante de emisiones de gases de efecto invernadero y, por lo tanto, la principal fuente del calentamiento global; que el uso de agroquímicos y pesticidas además de ocasionar la extinción de las abejas y otros animales, importantes en el proceso de reproducción vegetal, están generando daños a la salud humana; que el retiro de manglares para el desarrollo de actividades turísticas está teniendo como consecuencia principal la pérdida de biodiversidad; que la megaminería a cielo abierto y el fracking son la causa principal de la pérdida de cubierta vegetal, de la contaminación de los ríos y mantos acuíferos, y de la inestabilidad de los suelos; y que la "caza deportiva" y la venta de animales exóticos se están posicionando como una de las causas de la extinción de especies. Pese a que la ciencia y el conocimiento cotidiano ponen en evidencia los efectos negativos que estas prácticas tienen en el entorno natural, la sociedad capitalista, en busca de la valorización, insiste en mantenerlas.

En lo que toca a los virus, la ciencia médica y veterinaria han documentado ampliamente cómo en la industria agroalimentaria, particularmente en la cría porcina y avícola, el uso irracional de antivirales, antibióticos y otros fármacos hormonales, destinados al proceso de engorda y reproducción del animal, están haciendo que los patógenos se vuelvan más resistentes a dichos fármacos. Junto a esto, las condiciones de hacinamiento, maltrato animal y la falta de higiene e inocuidad con miras a reducir los costos de producción, son prácticas que están 
coproduciendo un ecosistema en el que los virus evolucionan, mutan, se reproducen y transfieren libre y eficazmente. De acuerdo con Silvia Ribeiro (2020), "más del $70 \%$ de los antibióticos a nivel global se usan para engorde o prevención de infecciones en animales no enfermos", de ahí que la misma autora señale que "la verdadera fábrica sistemática de virus y bacterias que se transmiten a humanos [sea] la cría industrial de animales". (s. p.). De hecho, ya la misma producción masiva de antibióticos nos habla de la enajenación de las prácticas productivas en el capitalismo, orientadas a incrementar la escala de la producción de alimentos cárnicos sin tomar en cuenta las consecuencias en la salud animal y humana que se derivan precisamente de estas prácticas.

Por su parte, la industria de alimentos ultraprocesados, con alto contenido calórico, constituye otro proceso de fractura metabólica en el sentido de que se está produciendo un ecosistema en el que la vulnerabilidad inmunológica de los seres humanos potencia la dinámica que los virus tienen para generar enfermedades. En el caso de México, por ejemplo, tanto las autoridades sanitarias como diversos científicos nacionales, han señalado que la industria de alimentos "chatarra", es decir, alimentos con alto contenido en azúcares y grasas, producidos en grandes cantidades y que son de fácil acceso sobre todo para la población juvenil, es la principal causa de enfermedades crónicas como la diabetes, la hipertensión y la obesidad. De acuerdo con la Organización para la Cooperación y el Desarrollo Económico (OCDE), México es el país con la mayor tasa de enfermedades crónicas en América Latina, ${ }^{5}$ situación que junto con la falta de inversión, desmantelamiento y privatización de los sistemas de salud pública, principalmente ocurrido durante los gobiernos neoliberales, son algunos de los procesos sociales que dieron forma a un metabolismo social en el que el coronavirus encontró las condiciones materiales idóneas para causar enfermedades y muertes a la población. ${ }^{6}$

5 Véase el reportaje titulado "México, el país con mayor obesidad de AL: OCDE", en periódico $L a$ Jornada del 16 de julio de 2020. Disponible en www.lajornada.com.mx (1 de agosto de 2020).

${ }^{6}$ De acuerdo con información oficial, en México ya se registran más de 2362800 contagios totales en los primeros días de marzo de 2021 y alrededor de 195110 muertes por COVID-19, lo que lo coloca como uno de los países con mayor tasa de mortalidad. Como se ha indicado, estos datos se explican en buena medida por la gran presencia de enfermedades crónicas, así como por el abandono del sistema de salud pública caracterizado por una significativa falta de medicamentos, el deterioro o inexistencia de infraestructura hospitalaria y un reducido personal médico. 
En el mismo sentido, la actual pandemia no puede ser explicada sin considerar el dominio que el capitalismo ejerce sobre el desarrollo científico y tecnológico. El principio del "cálculo económico" que rige las decisiones sobre la inversión y el emprendimiento de innovaciones farmacéuticas ha llevado a esta industria, controlada principalmente por particulares, a desarrollar (o no desarrollar) fármacos y vacunas de acuerdo con las necesidades de rentabilidad y no tanto así de su capacidad para curar enfermedades o evitar epidemias. Existen numerosos casos en los que las grandes farmacéuticas prefieren invertir en el desarrollo de fármacos que controlen determinadas enfermedades en lugar de curarlas (como es el caso del VIH), así como de la falta de interés en el desarrollo de vacunas antes del surgimiento de posibles epidemias pese a los múltiples estudios científicos que señalan la probabilidad que ciertos virus tienen para transferirse a los humanos y generar enfermedades

En el caso de los coronavirus, éstos ya se conocían desde los años setentas y, después de las experiencias epidémicas relacionadas con el SARs (Síndrome respiratorio agudo severo) en 2002 y con el MERs (Síndrome respiratorio de Medio Oriente) en 2012, se llegaron a plantear análisis prospectivos, en 2014 y 2015, que señalaban no sólo la enorme probabilidad de que una nueva epidemia relacionada con este tipo de virus pudiera surgir en los próximos años dadas la enorme expansión de actividades agroalimentarias y las prácticas depredadoras del medio ambiente, sino además los alcances e impactos sociales que dicha pandemia tendría dado el incremento de los medios de transporte, la movilidad masiva de personas y el crecimiento del comercio mundial. ${ }^{7}$ De hecho, tanto la epidemia del sars como la del MERS dan cuenta de cómo el desarrollo de vacunas sigue un camino completamente azaroso en función de los requerimientos del mercado.

En una entrevista realizada por la BBC a la Dra. Elena Bottazi, codirectora de la Escuela Nacional de Medicina de Houston, ésta señaló que, tras las investigaciones desarrolladas en torno a las epidemias del SARS y el MERS, era perfectamente posible

7 Al respecto, puede consultarse el artículo "Coronavirus ¿la próxima pandemia?" publicado el 1 de julio de 2014. Disponible en: https://lacienciaysusdemonios.com/2014/07/01/coronavirus-la-proxima-pandemia/ (29 de agosto de 2020). Así mismo, la ponencia presentada en 2015 por Bill Gates en un evento de Tecnología, Entretenimiento y diseño (TED) en el que habla sobre una posible epidemia por coronavirus, son muestra de las predicciones científicas en torno a la probabilidad de surgimiento de nuevas pandemias. Video disponible en https://youtu.be/6Af6b_wyiwwl (13 de agosto de 2020). 
que la humanidad hubiera estado preparada para enfrentar la pandemia del SARSCoV-2 mediante la existencia de vacunas piloto, mayores ensayos clínicos y una base científica sólida sobre el comportamiento de los coronavirus. No obstante, la contención en la propagación del SARs hacia el segundo semestre de 2003 llevó a las fuentes de financiamiento público y privadas a perder interés por el estudio de los coronavirus y, por lo tanto, a dejar de financiar las investigaciones ya que, como lo señaló el virólogo Peter Kolchinsky, miembro del equipo de Houston, "no había un mercado para la vacuna", advirtiendo además que "el problema es que para cualquier compañía es una terrible propuesta empresarial desarrollar un producto que, según las probabilidades, no será utilizado en décadas o quizás nunca". (Nava, 2020: s. p.).

Lo anterior muestra que pese a la urgente necesidad que tiene la humanidad por enfrentarse a las enfermedades zoonóticas y a la propagación de los virus, el control que ejerce el capital sobre el desarrollo médico y farmacéutico ha impedido la producción de vacunas en tanto que las condiciones del mercado no prevén una ganancia sobre la inversión. Esto contrasta con la situación actual en la que, con una pandemia en franco ascenso y en vista de un mercado con más de 7 mil millones de potenciales clientes, las grandes farmacéuticas están compitiendo frenéticamente por producir y comercializar sus vacunas y de ese modo quedarse con una jugosa ganancia. Es de esta manera que, pese al potencial que hoy en día tiene la ciencia para anticiparse a la formación de una epidemia, las experiencias del SARS y el MERS muestran cómo la lógica del valor, inherente a las prácticas productivas de los consorcios farmacéuticos, traba el desarrollo científico con miras al valor de uso, imposibilitando de esta manera la configuración de un metabolismo social materialmente capaz de hacer frente a los patógenos.

El actual acaparamiento y acceso desigual a las vacunas producidas por Pfizer, AztraZeneca, Johnson \& Johnson entre otros grandes consorcios farmacéuticos, pone en evidencia la fragilidad e incertidumbre de la vida humana frente a los intereses económicos y políticos de los países desarrollados como Estados Unidos y Europa en la medida en que éstos mantienen el control de la producción y de las patentes o licencias farmacéuticas — patentes consagradas por la Organización Mundial del Comercio (OMC) — impidiendo con ello que las naciones menos desarrolladas, pero con capacidad tecnológica para hacerlo - tanto en América Latina, como en África y el Sureste asiático_- , puedan producir las vacunas para atender a su población, por lo que a decir de Joseph Stiglitz (Premio Nobel de Economía), la carencia mundial 
de vacunas es artificial, ya que "hay muchas empresas en países en desarrollo que podrían producir cantidades masivas de vacunas si tuvieran la propiedad intelectual, si les [dan] acceso a la tecnología" (Stiglitz en Brooks, 2021: s. p.)

Estos son algunos de los procesos sociales a través de los cuales la sociedad capitalista ha participado activamente en la producción de la pandemia. La explicación del origen de la fractura metabólica que se vive actualmente en forma de crisis sanitaria requiere, por lo tanto, del reconocimiento de la lógica del valor como proceso enajenante de las relaciones sociales y, en consecuencia, como proceso de construcción de una realidad material en tanto que ecosistema que hace a los seres humanos susceptibles a enfermedades virales. Pensar la pandemia en estos términos nos impulsa a ir más allá de la "nueva normalidad" y de las estrategias imperantes que se articulan actualmente para salir de la crisis y nos coloca frente a una posición crítica de la forma social contemporánea, al mismo tiempo que nos invita a pensar nuevas formas de organización social que establezcan una relación más armónica con la naturaleza.

\section{Conclusión}

Más allá del abandono de los sistemas de salud pública; del control que ejerce la iniciativa privada en el desarrollo médico, farmacéutico y tecnológico; y de la presencia de enfermedades crónicas relacionadas con una alimentación deficiente, la pandemia del coronavirus vino a poner de manifiesto la compleja relación que las sociedades humanas establecen con la naturaleza y, en particular, la conflictiva relación que el capitalismo mantiene con ésta dada la lógica del valor que subsume las acciones humanas.

La producción de un metabolismo social acorde con el proceso de valorización, además de evidenciar el sentido de las prácticas productivas que difícilmente escapan a la racionalidad mercantil, da cuenta en la actual pandemia de las desigualdades socio-económicas que caracterizan a las sociedades modernas y que de hecho se manifiestan a través de la "selectividad" que el coronavirus ejerce sobre los distintos grupos humanos, es decir, afectando de forma significativa principalmente a los grupos vulnerables de escasos recursos dadas sus limitaciones para acceder no sólo a tratamientos médicos inmediatos y de calidad, sino también a alimentos nutritivos 
y saludables, a agua suficiente y potable, a viviendas dignas y a sistemas de información confiables y oportunos.

Frente a la crisis sanitaria que atravesamos y en vista del colapso climático en puerta, hoy se hace necesario no sólo reconocer críticamente la subordinación que el capitalismo ejerce sobre las prácticas humanas; sino de reconocer que dichas prácticas pueden ser transformadas y orientadas hacia un proyecto político verdaderamente humano. Se trata, pues, de reconocer que en medio de la emergencia que estamos viviendo, surge la necesidad de reestablecer la lógica del valor de uso con miras a la realización de una forma social en cuyo régimen metabólico se produzca una relación sociedad-naturaleza armónica. Dicho reconocimiento será fundamental para superar la crisis sanitaria con éxito en la medida en que se entienda que, por lo menos, la salud pública debe ser forzosamente un bien común, libre de cualquier cálculo económico e interés particular.

Así mismo, es preciso reconocer que en tanto seres humanos somos parte de la naturaleza y de las complejas interrelaciones que surgen al interior de ésta. Decir que con nuestras prácticas invadimos y destruimos ecosistemas puede ayudarnos a enfocar el problema de la transmisión de los virus que ocurre de animales a humanos, pero no nos sirve de mucho cuando observamos que la especie humana produce y forma parte de muchos ecosistemas. Pensar que los virus se encuentran en entornos naturales aislados y que mantenernos a distancia es suficiente para evitar la transmisión es no reconocer que hemos convivido con ellos a lo largo de millones de años e igualmente es no comprender la enorme capacidad que estos organismos tienen para transmitirse de especie en especie. En este sentido, no se trata de aislarnos de los ambientes naturales "prístinos", de no expresar nuestras fuerzas naturales más allá de los "ambientes humanos" o de evitar participar en la modificación de ecosistemas; de lo que se trata de es producir un metabolismo social armónico, es decir, una realidad material que nos permita aprovechar lo positivo de los virus, al mismo tiempo de descartar la capacidad que tienen de afectar nuestra salud.

La "nueva normalidad" que hoy se impone a nivel mundial mantiene mucho de lo viejo y contiene poco de lo nuevo. La "nueva normalidad" es una reedición de la vieja cotidianidad en la que poco se cuestiona las causas reales que derivaron en el surgimiento de la pandemia y en la que sólo se aspira a controlar los síntomas de la crisis. Frente y contra a esta nueva normalidad, intelectuales de todo el mundo están poniendo en la mesa de discusión, como un primer horizonte, la urgente 
necesidad de convertir los sistemas de salud pública y el desarrollo médico y farmacéutico en bienes universales comunes a partir de los cuales se pueda garantizar las condiciones mínimas para la vida social. De concretarse lo anterior, ello se convertiría en una grieta en la estructura de dominación del capital que, de prolongarse, nos podría perfilar hacia la conformación de una nueva sociedad, es decir, una sociedad alternativa que, de acuerdo con Slavoj Žižek (2020), se presente como "una sociedad más allá del estado-nación, una sociedad que se actualiza a sí misma en las formas de solidaridad y cooperación global" (22). En última instancia, en una sociedad en la que nos reconozcamos no como dominadores de la naturaleza, sino como individuos pertenecientes a ella.

\section{Referencias bibliográficas}

Brooks, David. (2021, 17 de marzo). "Crecen en EU rechazo a patentes y apoyo a una 'vacuna del pueblo"” (en línea). La Jornada, Mundo. Recuperado el 17 de marzo de 2021 de https:// www.jornada.com.mx/notas/2021/03/17/mundo/crecen-en-eu-rechazo-a-patentes-y-apoyoa-una-vacuna-del-pueblo/

De Sousa Santos, Boaventura. (2020). La cruel pedagogía del virus. Consejo Latinoamericano de Ciencias Sociales (CLACSO).

ECHEVERríA, Bolívar. (1998). La contradicción del valor y el valor de uso en El Capital de Karl Marx. Itaca.

Europa Press. (2020, 27 de Julio). “Por qué todavía no hay vacuna contra el vih?” (en línea). Excelsior. Recuperado el 11 de agosto de 2020 de https:/www.excelsior.com.mx/trending/ por-que-todavia-no-surge-la-vacuna-contra-el-vih/1396314

Foster, John B. (2013). "Marx y la fractura en el metabolismo universal de la naturaleza". Herramienta. Revista de debate y crítica marxista.

Harvey, David. (2014). Diecisiete contradicciones y el fin del capitalismo. Traficantes de sueños.

Harvey, David. (2020). "Política anticapitalista en tiempos de COVID-19" (en línea). Revista Sin Permiso. Recuperado el 25 de junio de 2020 de https://www.sinpermiso.info/textos/ politica-anticapitalista-en-tiempos-de-covid-19

LEón, Efraín. (2016). Geografía Crítica. Espacio, teoría social y geopolítica. Itaca; UNAM.

Marx, Carlos. (2010). El Capital. Crítica de la economía política (Tomo I). Fondo de Cultura Económica.

Moutou, François. (2020, agosto). "Las zoonosis, entre humanos y animales" (en línea). Revista Nueva Sociedad. Recuperado el 20 de agosto de 2020 de https://nuso.org/articulo/laszoonosis-entre-humanos-y-animales/ 
Moya, Andrés; BAquero, Fernando. (2015). "La historia natural de las epidemias". Pasajes: Revista de pensamiento contemporáneo, (48), 12-18.

NAvA, Maria Elena. (2020, 9 de abril). "Coronavirus: cómo el mundo desaprovechó la oportunidad de tener una vacuna lista para hacer frente a la pandemia” (en línea). $B B C$ News, Mundo. Recuperado el 15 de agosto de 2020 de https://www.bbc.com/mundo/ noticias-52216766

Ribeiro, Silvia. (2020, 29 de febrero). "Coronavirus, agronegocios y Estado de excepción” (en línea). La Jornada, Economía. Recuperado el 13 de julio de 2020 de https://www.jornada. com.mx/ultimas/economia/2020/02/29/coronavirus-agronegocios-y-estado-de-excepcionsilvia-ribeiro-9431.html

SAITo, Kohei. (2017, marzo). "Marx en el Antropoceno: Valor, fractura metabólica y el dualismo no-cartesiano" (Cristián Peña Madrid, Trad.). Marxismo crítico. Recuperado el 25 de julio de 2020 de https://marxismocritico.com/2017/11/29/marx-en-el-antropoceno-valor-fracturametabolica-y-el-dualismo-no-cartesiano/

Smith, Neil. (2006). La producción de la naturaleza, la producción del espacio. (Claudia Villegas, Trad.). UNAM. (Obra original publicada en 1984).

Žižek, Slavoj. (2020). "Coronavirus es un golpe al capitalismo al estilo de 'Kill Bill' y podría conducir a la reinvención del comunismo". En Pablo Amadeo (Ed.), Sopa de Wuhan. Pensamiento contemporáneo en tiempos de pandemia (pp. 21-28). Aislamiento Social Preventivo Obligatorio. 